\title{
Comparing Road User Charging Acceptability in the City of Tunis and Damascus
}

\author{
Mohamad Shatanawi $^{1 a}$, Souhir Boudhrioua ${ }^{1}$ and Ferenc Mészáros ${ }^{1}$ \\ ${ }^{1}$ Department of Transport Technology and Economics, Faculty of Transportation Engineering and Vehicle Engineering, Budapest University \\ of Technology and Economics, Hungary
}

\begin{abstract}
Worldwide, multiple studies have been trying to reduce traffic issues without physically changing the road network, this is when the congestion fees strategy has been considered as a favorable solution for the urban traffic issues. A fundamental condition that needs to be checked before the implementation of the road-pricing scheme is the acceptability of both the political and the public parties. The acceptability is so variable and depends on many features and differs from one individual to another, thus, a survey with a set of variant questions might help to understand the expectations and the worries of the citizens and aim to improve them for better effectiveness of the road-pricing project. This report aims, through analyzing the responses of a distributed survey, to evaluate the acceptability of the citizens of Tunis, Tunisia and Damascus, Syria in order to draw a comparison between the two cities. Moreover, it assesses the degree of acceptability and the variable expectations of the implementation of the congestion fees of the two societies.
\end{abstract}

\section{Introduction}

Over recent decades, the increasing number of passenger cars increased the additional social costs such as wear and tear of the road network and time lost due to traffic congestion. This reason behind this is, based on the economic approach, once a resource is underpriced or free, then the demand will definitely exceed the supply. Similarly, if the number of vehicles in a road exceeds its capacity, congestion is created.[1] To solve this issue, physical interferences on the road is not always possible [2] and they are just short-term solutions that might even lead to more congestion in the future[3]. Thus, the road user charging was introduced as a tool that showed its effectiveness in managing the traffic flows and consequently the travel demand, and in reducing traffic jams.

One of the earliest road toll application was in 1971, where only the road network has been considered[4], while other experiences relied on the measurement of the congestion's externalities and the optimal charges that can be allocated to tackle traffic jam[5]. Many cities started the implementation of this strategy such as London or Milan, yet many others still struggle with the socio-political feasibility of such projects like in Auckland.

In London for example, the recommended implementation of the congestion charging began in February 2003 as an answer to the issue[6] where the commuters spent $50 \%$ of their travel time in traffic queues daily in 2008 [7] and the congestion cost was 2 to
4 million pounds weekly. Despite the critics of several stakeholder groups such as drivers, business owners, and politicians, in one month the project succeeded to decrease the traffic jams, improve the bus and the taxi services with the revenues, the overall public acceptance increased [8].

In Milan, the cordon-based pricing scheme in the city center, was introduced between 2008 and 2011, Ecopass, to basically face the pollution with a small effect on the road users and/or improve the share of public transportation [7]. Thus, the price depended on the emission class of the vehicle. The scheme helped to meet the initial pollution mitigation objective than later turned to a congestion reduction approach in 2012[1]. It was highly accepted thanks to the different types of discounts [7] and an upgrade to expand the system was voted by the citizens with $79 \%$ of favor who also supported to include all types of vehicles[9].

Auckland had one of the highest car share, $555 \mathrm{car} / 1000$ inhabitant since it is the most populated city of New Zeeland and has a low density and low public transport system [7]. Since 2005, researchers studied the acceptance of the congestion scheme but only $38 \%$ supported the project in 2005 and $25 \%$ in 2007[7]. The low public acceptance made the implementation of the scheme impossible to apply even after 13 years, which supports the idea that public acceptance is the key.

This paper studies the acceptability of road charging measures in two capitals, Tunis and Damascus, from two respective countries, Tunisia and Syria based on an online survey inspired the former survey[10], distributed

\footnotetext{
${ }^{a}$ Corresponding author: mshatanawi@edu.bme.hu
} 
among the residents. Authors analyze at first the socioeconomic variables, then traffic issues and their evolutions and the public and private acceptability at last. Finally, this helps in building a conceptual model targeting to improve the road charging acceptability. The parallel analysis aims to describe the differences and similarities between the two cities. The choice of the comparison between the two cities was made because of the similarities they share on different levels such as the socio-economic, the modal share of the transportation modes, the citizens' habits. Besides, both Tunisia and Damascus have a relatively rough political and economic situation.

The suggested congestion fees in the survey vary according to different time intervals for different zones in the city. Enforcement will be managed with cameras, which record all vehicle movements (enter or exit) in and out of the controlled zone. The proposed tariff strategy is the following as mentioned in Table 1:

Table 1. Toll Amount

\begin{tabular}{|c|c|c|}
\hline \multirow[t]{2}{*}{ Time } & \multicolumn{2}{|c|}{ Congestion Fee } \\
\hline & Tunis & Damascus \\
\hline From 06:00 to 09:00 & $1.0 \mathrm{TND}^{1}$ & $600 \mathrm{SYP}^{2}$ \\
\hline From $09: 00$ to $15: 00$ & $0.5 \mathrm{TND}$ & 300 SYP \\
\hline From $15: 00$ to $18: 00$ & $1.0 \mathrm{TND}$ & 600 SYP \\
\hline From $18: 00$ to $21: 00$ & $0.5 \mathrm{TND}$ & 300 SYP \\
\hline From $21: 00$ to $06: 00$ & 0.0 & 0.0 \\
\hline
\end{tabular}

All the revenues stemming from the road pricing system will be used as mentioned below:

- $50 \%$ of the revenues will be spent on the development of the public transportation network,

- $50 \%$ of the revenues will be spent on the improvement of the road network.

\section{Results and discussion}

This section analyzes the different responses of the aforementioned survey distributed to 250 residents in Tunis and the same in Damascus.

\subsection{Respondents analysis}

In this part, the background of the participants, as a sample of the society, is analyzed. The gender repartition of the respondents is similar between in the two capitals, a valid percentage of about $55 \%$ male and $45 \%$ female in both cities. Most of the respondents in Tunis are between 21 and 30 years while in Damascus between 21 and 40 years.

Most people have a driving license with a higher percent in Tunis (88\%) than in Damascus (78\%), however, slightly more people in Damascus own a vehicle. Around $50 \%$ and $45 \%$ of the participants respectively in Tunis and Damascus use vehicles to commute to work/school, the second most used mode of transport in both cities is public transport $(\mathrm{PuT})$, more commuters use it in Damascus. Few people walk or use bicycles for their trips, this reveals that the two cities are similar to the pattern of the transportation modes and that people are so dependent on their personal vehicles.

The analysis shows that having a vehicle influences the used mode of transport to commute to work/university where most of the respondents $(80 \%)$ in both cities who have car use it for work or school trip. The behavior of the commuters is affected by the income and the occupational status of the respondents. Most of the participants are employees in both cities, followed by freelancers in Damascus and students in Tunis. More freelancers in Damascus might justify the higher number of people owning a vehicle in Damascus

The analysis of the different features of the participants, have similarities in the citizens' behavior and their social background, which makes it easier to compare the acceptability between the two cities towards the implementation of the road charging scheme.

\subsection{Traffic problems analysis}

This part of the survey presents a set of questions aiming to determine the severity of the different traffic issues from the point of view of the participants.

The problems derived from the traffic can be classified into environmental problems (noise, air pollution, etc.), and problems directly related to the circulation of the traffic (Other problems). These two categories are shown in Figure 1. The hypothesis here is that if the respondents perceive these as a major or serious problem then they will likely be more ready to accept the pricing as a measure to solve these problems.

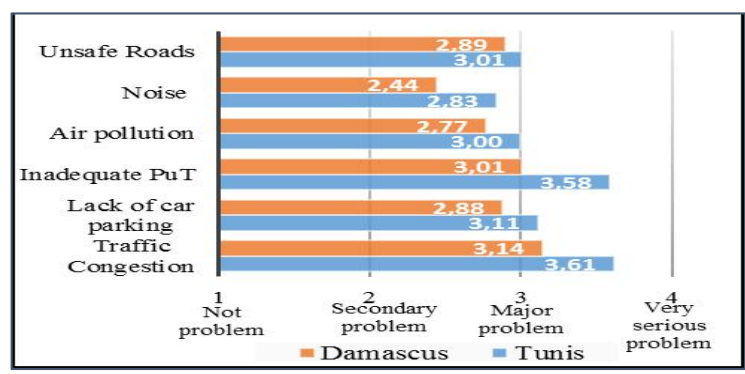

Figure 1. Traffic Issues Classification/ Mean values

The analysis shows that the awareness of the traffic problems is higher in Tunis, in both categories. However, in Damascus as well the problems are considered as major ones. Tunis's main problems are (1) the traffic congestion and (2) the inadequate and inefficient public transport (PuT) which are the main problems in Damascus. However, the problems mentioned above are considered serious in Tunis while they are major ones in Damascus. About the awareness of environmental problems, they are all considered major problems, but they are considered more serious in Tunis than in Damascus. There are many parties responsible when it comes to the issue of traffic. Figure 2 shows the responses' mean values regarding this matter. 


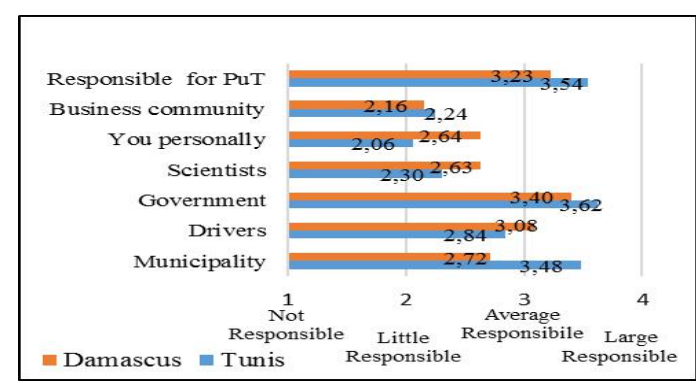

Figure 2. The parties responsible for traffic issues

Figure 2 explains that, in both cities, the respondents consider the authorities are responsible for the traffic problems, however, they feel more responsible in Tunis than in Damascus. The acceptability level is affected by whether respondents consider themselves as victims or contributors to traffic problems.

The last question was to understand the importance of different travel habits and whether they want to use their vehicles anytime and anywhere or they prefer other transport modes. Surprisingly the mean values of answers show high interest in all options. This contradicts can be interrupted as the respondents feel the necessity to use their vehicles due to the absence of the adequate alternative but hope for mobility development in the future.

\subsection{Study of the acceptance of the proposed scheme}

After the introduction of the scheme, the set of questions aim to capture preliminary opinions about the road charging concepts, such as the effectiveness, the effects on their mobility and travel behavior, the acceptance and the usage of raised fund.

The first studied point is the knowledge about the scheme by asking the participants to which extent they have heard about the pricing concept, Figure 3. Having information about the benefits of congestion pricing may increase the acceptability for, otherwise, it might be seen as a limitation of one's liberty.

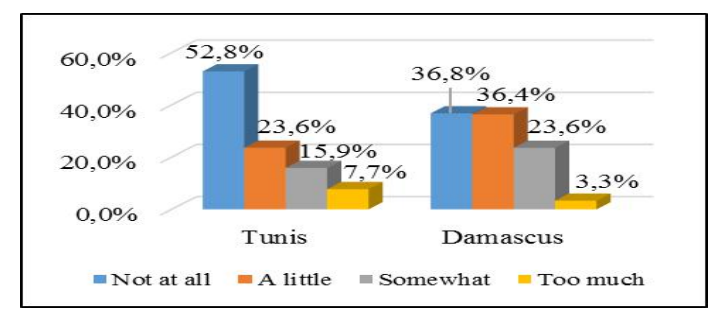

Figure 3. Knowledge about the proposed scheme

More than $70 \%$ of the respondents in both cities have not heard about road charging scheme or have just a little idea, which indicates the lack of information regarding the scheme in both cities.

The following question discuss the expected effectiveness of the road-charging scheme in reducing the traffic amount in both cities. If the respondents believe this measure is effective then their acceptance will be higher. A high expectation for the scheme effectiveness in Tunis as almost $65.7 \%$ of the respondents believe this measure will reduce the traffic amount in the city, while in Damascus half people think it could affect and other think it will not affect the traffic.

The acceptance for implementing the scheme is asked in the survey in two questions (1) about the public acceptability and (2) about the acceptability of his/ her family and close friends, individual acceptability

Answers are almost similar in both cities where slightly more than half respondents think that it would not be accepted by the public, where others believe the public will accept the measure. However, the percentage of those who think it is a completely acceptable strategy for the public is very small and those thinking it is totally unacceptable is forming a significant percent, which leads to considering higher refusal to the proposed scheme. Surprisingly, a higher level of acceptability can be seen when it comes to the expectation of the family and close friend's acceptability $62.6 \%$ in Tunis, $63.4 \%$ in Damascus.

The scheme may affect the several traveling habits of the daily commuters where the next question discusses these possible changes in case the scheme is implemented, and the provided questions can be grouped into two factors. The first is the positive changes by reducing the personal car trips and the second factor is the negative where the commuters will keep using the personal car with a slight shift in the times or the routes. Answers were based on a scale from 1 to 4 (where 1 is "No, for sure" and 4 is "Yes, for sure") and the mean results of all variable as seen in Table 2.

Table 2. Scheme Effects on the commuter's habits

\begin{tabular}{|l|cc|}
\hline & Tunis & Damascus \\
$\begin{array}{l}\text { I will drive the car less } \\
\text { I will use more the public } \\
\text { transport } \\
\text { I will use the bike more or walk } \\
\text { more }\end{array}$ & 2.55 & 2.48 \\
$\begin{array}{l}\text { I will pay the new fees and } \\
\text { continue driving as before }\end{array}$ & 2.33 & 2.63 \\
$\begin{array}{l}\text { I will not drive in tolled areas } \\
\text { I will share my car with my } \\
\text { colleagues and vice versa }\end{array}$ & 2.53 & 2.45 \\
$\begin{array}{l}\text { I will not drive during the } \\
\text { charging times } \\
\text { I will support the } \\
\text { demonstrations to stop the } \\
\text { project }\end{array}$ & 2.45 & 2.17 \\
\hline
\end{tabular}

Again, the answers are similar in both cities and the proposed scheme will not affect the travel habits significantly. The participants are moderate in their responses and there is no wish to protest. They would most likely either use public transport, bike or walk more.

The dependency on using the personal vehicle is an important factor in the acceptability for the road fees; the commuters who can reduce their trips with a personal car are more likely to accept the measure. The study shows a higher dependency on using a personal car in Damascus with $52.7 \%$ of people who disagree to significantly decrease the use of their vehicles. 
The respondents' anticipation for the elements affecting their trips are analyzed here, these elements are divided into two factors (1) favorable factor- respondents anticipate good results of implementing the scheme- and (2) unfavorable factors where the respondents anticipate bad results. The idea here if factor (1) is more anticipated by the respondents then the scheme will have more acceptability. The mean value of the answers which were designed on a scale 1 to 4 ( 1 is "No, for sure" and 4 is "Yes, for sure") are shown in Table 3.

The Tunisians respondents expect the proposed scheme to make the city a better place and reduce the travel time and environmental problems. Yet, Syrians in Damascus, the estimations are lower and additional travel costs are expected.

Table 3. The estimated consequences of the proposed scheme

\begin{tabular}{|l|cc|}
\hline & Tunis & Damascus \\
\hline Shorter travel time & 3.10 & 2.68 \\
Additional travel costs & 2.48 & 2.71 \\
Less environmental problems & 3.06 & 2.64 \\
Extra effort in planning trip & 2.74 & 2.52 \\
A nicer area (fewer vehicles) & 3.20 & 2.62 \\
Restricting my travel unfairly & 2.26 & 2.42 \\
\hline
\end{tabular}

The generated revenues from applying road charging scheme shall be used in benefits of the road users and the citizens, when asked how they shall be used and how might the government distribute them, the participants in Tunis highly agree to use them to improve the PuT, $93.3 \%$ and the movement of pedestrians and bikers, $91.2 \%$. Yet, they do not expect that the government would do so; but it would probably support the budget of the state or improve the traffic network such as roads. Contrarily to Tunis, in Damascus, there were no extreme choices, only for the case of the agreement on improving the PuT with $84.4 \%$ and unlike Tunis, the respondents agree to support of the budget of the state with $63.6 \%$. Similarly, to Tunis, the respondents disagree to decrease the customs fees on the vehicle and estimate that the government is likely to improve the infrastructure and support its budget.

\subsection{Multivariate Analysis}

This section discusses the further multivariate analysis that was used to examine what affects the acceptability of the scheme. In this manner, we used the dimension reduction technique or factor analysis "FA".

\subsubsection{Sensing the problems}

In this question (Figure 1) the aim is to evaluate the degree of sensing the traffic problems, the Cronbach Alpha test, for the six items, with an alpha coefficient of 0.72 , suggesting that the items have high reliability. Moreover, the Kaiser-Meyer-Olkin (KMO) test of 0.741 shows the sampling adequacy for the factor analysis of this question. There were two Eigenvalues greater than 1, hence two factors are retrieved explaining more than $60 \%$ of the total Variance of the data. The rotated component matrix shows which variables have the highest loadings within each factor. Using the Varimax rotation method guarantee that the variable can have a high loading in exactly one factor.

Accordingly, the process of simplifying and naming each factor become clear.

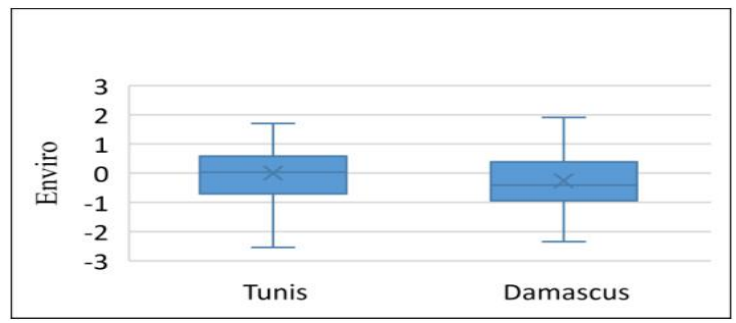

Figure 4. Problem sensing/ Environmental factor

The results retrieved two factors as follow (1) Environmental factor, which includes air pollution, traffic noise, and unsafe road, and (2) Service factor which includes traffic congestion, lack of adequate parking places, and inadequate public transport system. Figure 4 and Figure 5 displays the distribution of the factor scores of these two factors in both capitals, Tunis and Damascus.

The Boxplot shows a higher interest in environmental issues in Tunis compare to Damascus. The spread of the answers is approximately similar in both cities. However, there is a negative skewness in Tunis and positive skewness in the answers of Damascus which explain the wider range of responses in Tunis where there is a low percent consider the traffic-related problems as secondary problems.

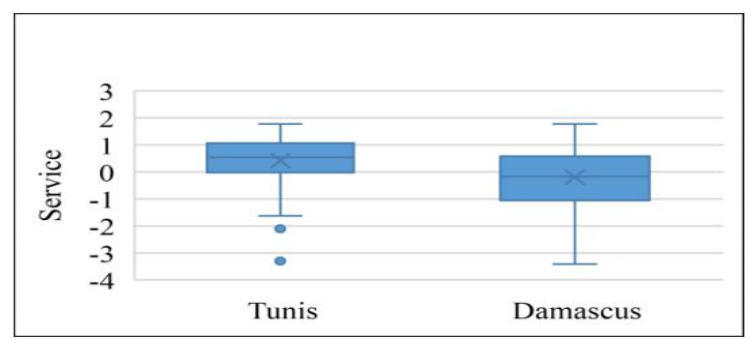

Figure 5. Problem sensing/ Service factor

Again, the median regarding the service factor is higher in Tunis compared to Damascus, which shows higher sensing for the problems in Tunis. As well as the answers look more consistent in Tunis with the existence of outliers where these outliers show the respondents who said the mentioned problems are not a problem at all or just secondary problems in Tunis. The skewness in both capitals is negative as fewer number of the respondents considered the traffic-related problems as secondary ones.

\subsubsection{Parties responsible for traffic issues}

The question which discusses the responsible for the traffic problems (Figure 2) consists of 7 elements, combining these elements gives true score variance with Cronbach's alpha of 0.688 . Factor analysis is possible as KMO test value is 0.744 and the Total Variance Explained table present two factors (Eigenvalue $>1$ ) 
where those two variables can be called as "Government" and "People" and they explain more than 55\% of all variables. Most Tunisians blame the government for the traffic problems, while opinions in Damascus are more moderate and with wider range, the reverse appeared when the second factor "People" was considered as it is seen in Figure 6, the Syrian believe they are more responsible for the traffic problems than Tunisians do, with smaller range and more consistency in the answers.

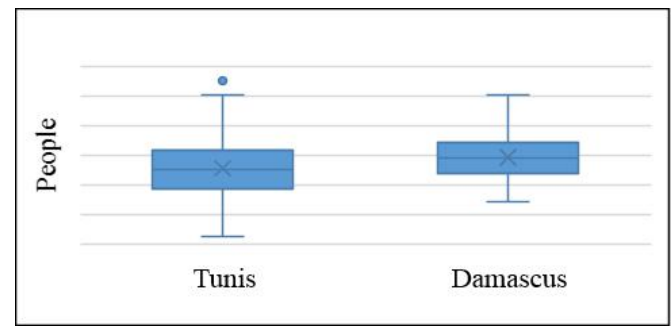

Figure 6. People responsibility for traffic problems according to respondents

\subsubsection{Acceptability}

There are two questions measure the direct acceptability the respondent's point of view for the acceptability of the society in general and the acceptability of their close friends and family member - these two questions were gathered, and boxplot was created to compare the two cities acceptability. Surprisingly, Figure 7 show very high similarity in both cities and with approximately similar median, minimum, maximum, and range.

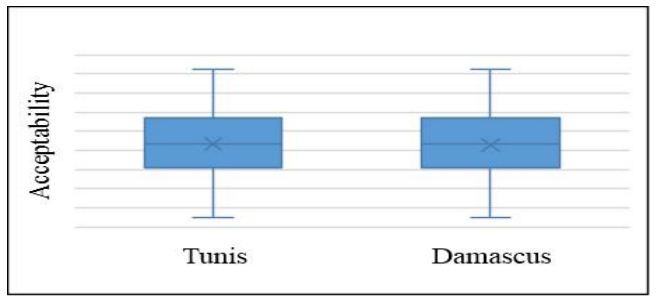

Figure 7. Acceptability of the scheme

\subsubsection{Anticipation for the trip elements after implementing the scheme}

The six elements in table 3 were gathered and tested, the Cronbach alpha is 0.585 for all elements where the KMO test gives a result of 0.670 and the total variance explained table suggests two factors which explain more than $63 \%$ of all variables. The rotated complement matrix gives two factors (1) favorable factor which includes item number 1, 3, and 5, Table 4, (2) unfavorable factors which include item number 2, 4, and 6 in the same table.

\begin{tabular}{|l|lcc|}
\hline No. & \multicolumn{1}{|c}{ Items } & \multicolumn{2}{c|}{ Factor loading } \\
\hline & & 1 & 2 \\
1 & Shorter travel time & 0.811 & -0.065 \\
2 & Additional travel costs & 0.001 & 0.740 \\
3 & Less environmental problems & 0.855 & 0.047 \\
4 & Extra effort in planning trip & -0.178 & 0.794 \\
5 & A nicer area (less vehicles) & 0.823 & 0.071 \\
6 & Restricting my travel unfairly & 0.240 & 0.672 \\
\hline
\end{tabular}

Table 4. Rotated component matrix

The positive expectation in Tunis is much higher than in Damascus in case the scheme was implemented, with more consistency in the answers and smaller range. The outliers show the few numbers who expected no good effect at all after implementing the scheme. On the other hand, the negative expectation is higher in Damascus and more consistency with a smaller range.

\section{Future Work}

This research is being expanded to include on one hand more cities in order to evaluate the acceptability conditions in Budapest, Ulaanbaatar, and Amman. On another hand, an application of the factor analysis to all questions of the survey shall be used as well as the regression analysis and other statistical methods to find the influencing factors on the acceptability of road charging scheme. Thus, the gathering would help create a conceptual model to improve the acceptability of the road charging scheme and to be used as reference or cornerstone.

\section{Conclusion}

Road charging scheme can be used as a measure to solve or reduce traffic-related issues by modifying the traveling behavior of the commuters. However, it is very difficult to convince the public to pay new fees for using roads where they did not use to pay for this before that is referred to as "low acceptability". This can be enhanced by using the right measures such as finding alternatives or better allocation of the revenue, etc. This paper focuses on the acceptability of road charging scheme in two capital cities (Tunis and Damascus). Although the two societies have similarities, the results show a different attitude towards traveling behavior and perspectives.

In both cities, people consider the traffic related issues as major problems with focusing on the service factor more than the environmental factor. Moreover, Tunisians are more frustrated with bad future expectation and blame the government for these problems, while Syrians see better future traffic situation and surprisingly, see themselves as a society more responsible. Moreover, Syrians have a better knowledge of the scheme. However, Tunisians have a more optimistic opinion for better mobility situation in case the scheme was applied to the city. These differences between the two societies dealing with different factors which affect the acceptability produce similar acceptability level in both capitals.

\section{References}

1. A. E. Ohazulike, E. C. Van Berkum, G. Still, and M. Bliemer, "Multi-objective road pricing: A cooperative and competitive bilevel optimization approach," p. 6, (Nov. 2010).

2. Gumz, F. and Török, Ádám. "Investigation of Cordon Pricing in Budakeszi", Periodica Polytechnica Transportation Engineering, vol. 43, no. 2, pp. 92-97, (2015) 
3. D. Pojani and D. Stead, "Sustainable Urban Transport in the Developing World: Beyond Megacities," Sustainability, vol. 7, no. 6, pp. 77847805, (Jun. 2015).

4. Dafermos, S.C., Sparrow, F.T., 1971. Optimal resource allocation and toll patterns in user optimized transport network". J. Transport Econ. Pol. 5, 198-200

5. Pigou, A.C., The economics of welfare. Transaction Publishers (1924)

6. T. Litman, "Congestion Pricing, Implications for Other Cities," Vic. Transp. Policy Institue, p. 14, (Nov. 2011).
7. V. Jarl, "Congestion pricing in urban areas: theory and case studies," Lund Institute of Technology, Department of Technology and Society, (2009).

8. T. Litman, "London congestion pricingimplications for other cities," Ifo Inst. Econ. Res. Munich, pp. 17-21, (2005).

9. G. Mattioli, M. Boffi, and M. Colleoni, "Milan's pollution charge: sustainable transport and the politics of evidence," White Rose Research, p. 17

10. J. Schade and B. Schlag, Acceptability of urban transport pricing. Helsinki: Valtion Taloudellinen Tutkimuskeskus, (2000). 